\title{
A STUDY OF EFFECT OF SPIRITUALITY AWARENESS ON STRESS MANAGEMENT IN MEDICAL STUDENTS
}

\author{
Shamim S. Sheikh ${ }^{1}$
}

${ }^{1}$ Associate Professor, Department of Pathology, M. P. Shah Government Medical College, Jamnagar, Gujarat, India.

ABSTRACT
BACKGROUND
The extreme stress level inherent in medical profession puts medical students at risk for both physical and psychological problems.
Inability to cope up successfully with the enormous demands of Medical Education and Medical Practice may lead to cascade of
consequences at both Personal and Professional level. This study focused on medical students as a preliminary attempt to identify
stressors and level of stress, by Medical Student Stressor Questionnaire (MSSQ) and scoring on it. The aim of study is to evaluate
spiritual awareness that can improve wellness of medical students and help them in stress management.

\section{MATERIALS AND METHODS}

This study was conducted with 2nd year M.B.B.S. students- major batch 172 students after approval of Local Ethical Committee. Prevalidated Medical Student Stressor Questionnaire (MSSQ) was used. Spirituality awareness sessions were conducted with two follow-up sessions monthly.

\section{RESULTS}

Stress level due to all stressors showed noticeable reduction after spiritual awareness sessions.

\section{CONCLUSION}

Spiritual awareness and regular practice of meditation may help in stress management.

\section{KEY WORDS}

Stress, Spiritual Awareness, Medical Student Stressor Questionnaire

HOW TO CITE THIS ARTICLE: Sheikh SS. A study of effect of spirituality awareness on stress management in medical students. J. Evolution Med. Dent. Sci. 2019;8(10):674-678, DOI: 10.14260/jemds/2019/150

\section{BACKGROUND}

The extreme stress levels inherent in medical profession put medical student at risk for both physical and psychological problems.(1) Inability to cope up successfully with the enormous demands of Medical Education and Medical practice may lead to cascade of consequences at bothPersonal and Professional level- influencing their effectiveness as doctors by diminishing the quality of doctorpatient relationship One or more of such stressors might act at the same time and contribute in development of stress among medical students Excessive amount of stress in medical training predisposes students to have difficulties in solving interpersonal conflicts, sleeping disorder, decreased attention, reduced concentration, temptation to cheat on exams, depression, loss of objectivity, increased incidence of errors, and improper behaviour, such as negligence. Stress may also manifest in the form of headaches, gastrointestinal disorders, coronary heart disease, impaired judgments, absenteeism, self-medication, suicidal ideation, depression and the consumption of drugs and alcohol.(2) There is need to prepare future doctors for stress in medical practice.

'Financial or Other Competing Interest': None.

Submission 10-01-2019, Peer Review 25-02-2019,

Acceptance 02-03-2019, Published 11-03-2019.

Corresponding Author:

Dr. Shamim S. Sheikh,

39-B, Paras Society,

Asopalay Mars,

Jamnagar, Gujarat,

India.

E-mail: drshamim1973@gmail.com

DOI: $10.14260 /$ jemds $/ 2019 / 150$
This study was focused on medical students as preliminary attempt to identify stressors and level of stress by Medical Student Stressor questionnaire (MSSQ) and scoring on it.

MSSQ comprised of six categories of stressors i.e. ARS=Academic Related Stressor, IRS= Inter active/Inter personal related stressor, TLRS $=$ Teaching Learning related stressor, SRS $=$ Social stressors, DRS $=$ Drive/Desire related stressor, GARS= Group activity related stressor. (Muhmmod SBY et al 2010). This study also assesses the effectiveness of spiritual wellness for stress management by cultivating spirituality awareness. The term wellness is used to mean healthy balance of-Body, Mind and Spirit with feeling of wellbeing. Spiritual wellness is one of the area which promote self-directed efforts of life-long learning by stress management.(3)

\section{Aims \& Objectives}

\section{Aim}

Spiritual awareness that can improve wellness of medical students and help them in stress management.

\section{Objectives}

1. To identify stressors and level of stress in medical students.

2. To assess effectiveness of spirituality awareness for stress management in medical students. 


\section{MATERIALS AND METHODS}

Study Type

Descriptive.

\section{Study Subjects}

Second year M.B.B.S students of M. P. Shah Medical College, Jamnagar.

\section{Study Duration}

1 year (Feb 2017 to Feb 2018).

This study was conducted with $2^{\text {nd }}$ year M.B.B.S. students - major batch 172 students after approval of Local Ethical Committee.

All students were explained about project in detail; 150 students were volunteered to identify stressors causing stress and level of stress.

Pre - validated Medical Student Stressor Questionnaire (MSSQ) was used. MSSQ consists of six hypothetical domain categories to stressors - ARS=Academic Related Stressor, IRS= Inter active/Inter personal related stressor, TLRS= Teaching Learning Related Stressor, SRS= Social Stressors, DRS $=$ Drive/Desire Related Stressor, GARS= Group Activity Related Stressor. (Muhmmod SBY et al 2010) with 40 items (Annexure - I). Scoring scale was used to grade the level of stress. ${ }^{(4)}$

\section{Spirituality awareness sessions were conducted with two} follow-up sessions monthly. Sessions comprised of-

1. Spiritual wellness awareness lecture-20 min

2. Pranayama (Breathing exercise).

3. Transcendental sitting meditation-20 $\mathrm{min}$.

Immediate post-session feedback was taken (Annexure II). Regular practice was advised. After second follow-up session spiritual experiences were assessed by Index of Core Spiritual Experiences (INSPIRIT) (Annexure -III)(5) to know the spiritual awareness and wellness.

\section{Statistical Analysis}

Statistical analysis was done using the software SPSS version 21. Mean of Pre-test session and Post-test session for all the parameters were compared using Paired samples t-test. Cognitive gain was calculated as Post-test score minus Pretest score. For all statistical evaluations, probability of value $<0.05$ was considered significant.

\section{RESULTS}

\begin{tabular}{|l|c|c|c|c|c|c|}
\hline Level of stress & $\begin{array}{c}\text { ARS } \\
\mathbf{\%}\end{array}$ & $\begin{array}{c}\text { IRS } \\
\mathbf{\%}\end{array}$ & $\begin{array}{c}\text { TLRS } \\
\mathbf{\%}\end{array}$ & SRS & $\begin{array}{c}\text { DRS } \\
\mathbf{\%}\end{array}$ & $\begin{array}{c}\text { GARS } \\
\%\end{array}$ \\
\hline Mild/No Stress & 12 & 28 & 28 & 34 & 55 & 38 \\
\hline Moderate & 63 & 55 & 59 & 54 & 35 & 45 \\
\hline High & 24 & 19 & 13 & 12 & 08 & 16 \\
\hline Severe & 01 & 00 & 00 & 00 & 02 & 01 \\
\hline Table I. Pre-Session Assessment of Stressors and Stress Level \\
Scoring \\
\hline \multicolumn{7}{|c|}{ Significant p<0.05 } \\
Shows results of stressor identification and level of stress \\
caused by those stressors. 63\% of students suffer from \\
moderate stress and 24\% high level stress by ARS. ARS was \\
identified as the most common stressor among medical \\
students. TLRS and IRS cause moderate level stress in 59\% \\
and 55\% of students respectively. IRS was identified the \\
second most common stressor causing high level of stress in \\
19\% of students. Even though DRS causes Mild/no stress in \\
maximum percentage of students i.e. 55\%; it also causes \\
severe stress in 2\% of students. SRS and GARS were \\
considered stressors causing mild stress or no stress. \\
\hline
\end{tabular}

\begin{tabular}{|c|c|}
\hline Sessions & No. of Students \\
\hline 1st Main Session & $150(100 \%)$ \\
\hline Follow Up 1st & $120(80 \%)$ \\
\hline Follow Up 2nd & $122(81 \%)$ \\
\hline \multicolumn{2}{|c|}{ Table II. Attendance of Students }
\end{tabular}

Table II. Attendance of Students

In $1^{\text {st }}$ and $2^{\text {nd }}$ follow-up sessions attendance of students was $80 \%$ and $82 \%$ respectively. Immediate feedback questionnaire revealed that session was well conducted, and they will take out time for meditation. In $1^{\text {st }}$ and $2^{\text {nd }}$ follow-up sessions attendance of students was $80 \%$ and $82 \%$ respectively. Immediate feedback questionnaire revealed that session was well conducted, and they will take out time for meditation.

\begin{tabular}{|c|c|}
\hline Spiritual Experiences & No. of Students \\
\hline High & $12(10 \%)$ \\
\hline Medium High & $28(23 \%)$ \\
\hline Medium Low & $59(48 \%)$ \\
\hline Low & $23(19 \%)$ \\
\hline Total & $\mathbf{1 2 2 ( 1 0 0 \% )}$ \\
\hline
\end{tabular}

\section{Table III. Spiritual Experiences Assessed by Inspirit}

After all three sessions $48 \%$ of students had medium low spiritual experience while $10 \%$ students had high spiritual experiences

\begin{tabular}{|c|c|c|c|c|c|c|}
\hline $\begin{array}{c}\text { Level of } \\
\text { stress }\end{array}$ & $\begin{array}{c}\text { ARS } \\
\text { (\%) }\end{array}$ & $\begin{array}{c}\text { IRS } \\
\text { (\%) }\end{array}$ & $\begin{array}{c}\text { TLRS } \\
\text { (\%) }\end{array}$ & $\begin{array}{c}\text { SRS } \\
\text { (\%) }\end{array}$ & $\begin{array}{c}\text { DRS } \\
\text { (\%) }\end{array}$ & $\begin{array}{c}\text { GARS } \\
\text { (\%) }\end{array}$ \\
\hline $\begin{array}{c}\text { Mild/no } \\
\text { stress }\end{array}$ & 36 & 52 & 36 & 48 & 77 & 57 \\
\hline Moderate & 47 & 49 & 50 & 50 & 18 & 29 \\
\hline High & 16 & 9 & 14 & 2 & 5 & 14 \\
\hline severe & 00 & 00 & 00 & 00 & 00 & 00 \\
\hline
\end{tabular}

Table IV. Post Session Assessment of Stress Level with Stressors

Significant $\mathrm{p}<0.05$

Post- session's assessment of stress level for all six stressors repeated to observe effect of spiritual awareness.

\begin{tabular}{|c|c|c|c|c|c|c|c|c|c|c|c|c|}
\hline \multirow[b]{2}{*}{$\begin{array}{l}\text { Level of } \\
\text { stress }\end{array}$} & \multicolumn{2}{|c|}{$\begin{array}{l}\text { ARS } \\
(\%)\end{array}$} & \multicolumn{2}{|c|}{ IRS (\%) } & \multicolumn{2}{|c|}{$\begin{array}{c}\text { TLRS } \\
(\%)\end{array}$} & \multicolumn{2}{|c|}{$\begin{array}{l}\text { SRS } \\
(\%)\end{array}$} & \multicolumn{2}{|c|}{$\begin{array}{l}\text { DRS } \\
(\%)\end{array}$} & \multicolumn{2}{|c|}{$\begin{array}{c}\text { GARS } \\
(\%)\end{array}$} \\
\hline & $\stackrel{D}{0}$ & $\stackrel{\vec{b}}{a}$ & 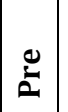 & $\begin{array}{l}\vec{v} \\
\dot{0} \\
\dot{a}\end{array}$ & 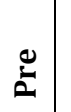 & $\dot{\vec{b}}$ & 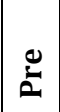 & 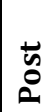 & $\stackrel{2}{2}$ & 㫄 & $\stackrel{D}{D}$ & $\begin{array}{l}\vec{\Delta} \\
\stackrel{0}{a}\end{array}$ \\
\hline $\begin{array}{l}\text { Mild/1 } \\
\text { stres }\end{array}$ & 12 & 36 & 28 & 52 & 28 & 36 & 34 & 48 & 55 & 77 & 38 & 57 \\
\hline Moderate & \begin{tabular}{|l|}
63 \\
\end{tabular} & \begin{tabular}{|l|}
47 \\
\end{tabular} & 55 & 49 & 59 & 50 & 54 & 50 & 35 & 18 & 45 & 29 \\
\hline High & 64 & 16 & 19 & 09 & 13 & 14 & 12 & 02 & 08 & 05 & 16 & 14 \\
\hline Severe & 01 & 00 & 00 & & & 00 & & & & & & 00 \\
\hline \multicolumn{13}{|c|}{$\begin{array}{c}\text { Table V. Comparison of Parameters of Pre and Post Session } \\
\text { Intervention }\end{array}$} \\
\hline \multicolumn{13}{|c|}{$\begin{array}{l}\text { Significant decrease i.e., from } 63 \% \text { to } 47 \% \text { observed in } \\
\text { students having moderate level of stress with ARS. Increase } \\
\text { in students with mild/no stress with ARS } \quad 36 \%) \\
\text { suggest positive effect of spiritual awareness. Significant } \\
\text { effect was noticed with DRS and GARS by increase in } \\
\text { percentage of students with mild/no stress i.e. } 77 \% \text { and } 57 \% \\
\text { respectively. Severe stress was relieved to moderate level } \\
\text { with DRS. }\end{array}$} \\
\hline
\end{tabular}



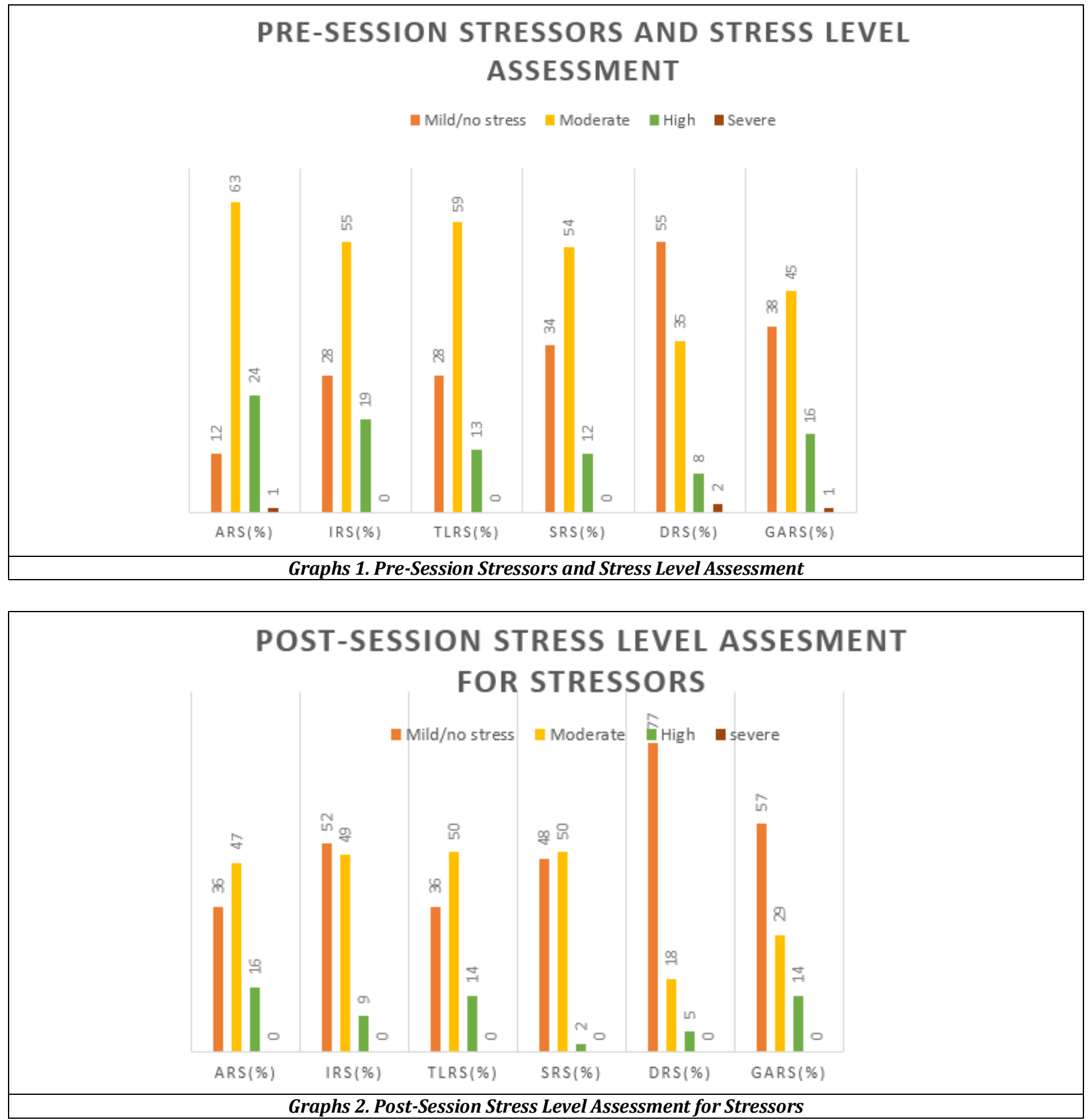

\section{COMPARISON OF PARAMETERS OF PRE AND POST SESSION INTERVENTION}

Mild/nostress moderate $\mathbf{H i g h}$ - Severe

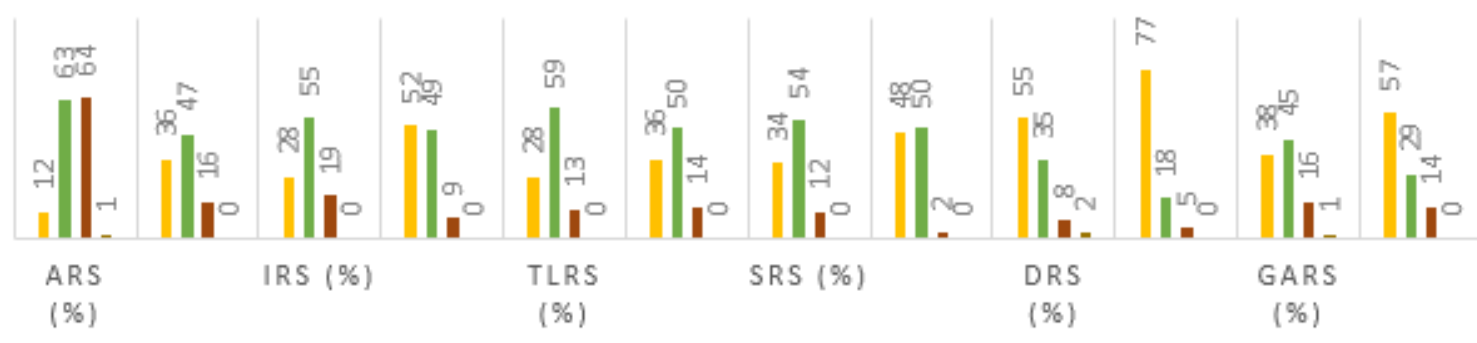

Graph 3. Comparison of Parameters of Pre and Post Session Intervention 


\section{DISCUSSION}

Stress is defined as an imbalance between environmental conditions necessary for survival and ability of individual to adapt those conditions. $(6,7)$

Personal and environmental events that cause stress are known as stressors.(8) In MSSQ stressors of medical students are grouped into six categories.

The most common stressor identified in study was Academic Related Stressor causing moderate level of stress followed by Teaching - Learning related and Inter/Intra personal related stressor. $61 \%$ of students perceived moderate level of stress findings were well correlated with Umesh et al.(6) \& Yusoff et al.(4) These stressors followed by SRS, GARS and DRS causing moderate level of stress i.e., 54\%, $45 \%$ and $35 \%$ respectively. Though DRS is causing mild/no stress in $55 \%$ of students; it causes severe stress in $2 \%$ of students and that $2 \%$ of students becomes vulnerable to drop from the course or suicidal attempts. These findings are well correlated with study by Umesh Shelke et al.

Spirituality may be a buffer to the negative effect of stressors.(9) Spirituality can enhance physical and psychological wellbeing.

Index of core spiritual experiences-INSPIRIT developed by KASS and colleagues 1991(5) demonstrates high internal reliability (Alpha coefficient 0.9. pre-validated). Assesses element of core spiritual experience i.e The perception of internalized relationship with GOD/ some form of Higher Power as defined by the person.(10,11) INSPIRIT was used to assess spiritual experience after both follow-up sessions showed $10 \%$ of students with high and $48 \%$ of student with medium low spiritual experience this was correlated with study of Kabtt Zinn et al (1996).(12) They have used mindfulness meditation among non-clinical subjects.

Post session stress scoring revealed significant decrease in level of stress in all stressors which was supported by the study done by Shapirio et al(10) that denotes decrease in state of anxiety after spiritual awareness.

\section{My Reflections}

\section{What Was Good?}

1. Cooperation of students.

2. Immediate feedback was positive.

3. Attendance of students in follow-up sessions.

4. Commitment for regular practice.

\section{What Could Have Been Different?}

1. More time is required to assess the spiritual experiences.

2. Focused group feedback may improve the effect of spiritual awareness on stress management.

3. DRS and IRS could be the stressors of $1^{\text {st }}$ year students.

\section{What This Study Adds}

1. ARS common stressor identified to cause moderate level of stress.

2. Spiritual awareness and regular practice of meditation can decrease stress level on medical students.

\section{The Road Ahead}

1. Spiritual awareness sessions can be the strategy for stress management and need to be included in curriculum to improve learning.

2. Further research for long period of time is required.

\section{Implications}

- Spiritual awareness sessions can be the strategy for stress management and need to be included in curriculum to improve learning.

- Further research for long period of time is required.

- Future research is encouraged to explore physiological effect of spiritual wellness to eliminate response bias.

- Spiritual awareness sessions can be incorporated into curriculum as stress management strategy.

\section{Limitations}

- This study was based on perception of students and has qualitative analysis subjective factor can affect the results.

- Control group was not available.

- Time constraint long term study is required.

- Pilot study is advisable before using pre-validated questionnaire.

- As this study was carried out in $2^{\text {nd }}$ year so DRS was managed in 1 st year.

\section{CONCLUSION}

- $\quad$ ARS followed by TLRS and IRS are common stressors identified to cause moderate level of stress.

- $\quad$ DRS though in less students but can cause severe stress level.

- Spiritual awareness and regular practice of meditation can reduce level of stress in medical student.

- $\quad$ TLRS had less effect of spiritual awareness while with IRS decrease in level of stress was observed.

\section{REFERENCES}

[1] Johnson NP, Michels PJ, Thomas JC. Screening tests identify the prevalence of alcohol use among freshman medical students and among students' family of origin. J South Carolina Med Assoc 1990;86(1):13-4.

[2] Lee C. Professionals in medical settings: the research evidence in the 1980s. J Org Behav Mgt 1987;8(2):195-214.

[3] Rehman R, Syed S, Hussain M, et al. Health and spirituality 'walk along' in wellness journey of medical students. J Pak Med Assoc 2013;63(4):495-500.

[4] Yusoff MSB, Rahim AFA, Yaacob MJ. The development and validity of the Medical Student Stressor Questionnaire (MSSQ). ASEAN Journal of Psychiatry 2010;11(1):1-12. http://www.aseanjournalofpsychiatry.org/oe11105.h tm

[5] Kass J, Friedman R, Leserman J, et al. Health outcomes and a new measure of spiritual experience. J Sci Study Rel 1991;30(2):203-11.

[6] Umesh SS, Rahul KR, Sandeep NP. Level of stress in final year MBBS students at rural medical college: a cross-sectional study. Int J Med Res \& Health Sci 2014;3(4):886-91.

[7] Rosenham DL, Seligman ME. Abnormal psychology. 2nd edn. New York: Norton 1989.

[8] Lazarus RS, Folkman S. Stress, appraisal and coping. New York: Springer Press 1984. 
[9] Kass J. Contributions of religious experience to psychological and physical well-being: research evidence and an explanatory model. In: VandeCreek L, edr. Spiritual needs and pastoral services: readings in research. Decatur, Georgia: Journal of Pastoral Care Publications 1995: p. 189-213.

[10] Shapiro DH. Overview: clinical and physiological comparisons of meditation with other self-control strategies. Am J Psychiat 1982;139(3):267-74.
[11] https://www.scribd.com/document/49945421/Index -of-Core-Spiritual-Experiences

[12] Kabat-Zinn J. Mindfulness meditation: What it is, what it isn't and its role in health care and medicine. In: Haruki Y, Ishii Y, Suzuki M, eds. Comparative and psychological study on meditation. Eburon, Netherlands: 1996: p. 161-70. 